\title{
Sequential solvent extraction for the modes of occurrence of selenium in coals of different ranks from the Huaibei Coalfield, China
}

\author{
Ying Zhang1, Guijian Liu*1, Chen-Lin ${ }^{*}{ }^{2}{ }^{2}$, Lei Wang1 and Yu Kang1
}

Address: ${ }^{1}$ CAS Key Laboratory of Crust-Mantle Materials and the Environment, School of Earth and Space Sciences, University of Science and Technology of China, Hefei 230026, China and 2Illinois State Geological Survey (Emeritus), Champaign, IL 61820, USA

Email: Ying Zhang - gjl0607@163.com; Guijian Liu* - yangpy@ustc.edu.cn; Chen-Lin Chou - chenlinchou@hotmail.com; Lei Wang -wl163@163.com; Yu Kang - lgj@ustc.edu.cn

* Corresponding author

Published: 20 December 2007

Geochemical Transactions 2007, 8:14 doi:10.1186/1467-4866-8-14
Received: 27 August 2007

Accepted: 20 December 2007

This article is available from: http://www.geochemicaltransactions.com/content/8/I/14

(C) 2007 Zhang et al; licensee BioMed Central Ltd.

This is an Open Access article distributed under the terms of the Creative Commons Attribution License (http://creativecommons.org/licenses/by/2.0), which permits unrestricted use, distribution, and reproduction in any medium, provided the original work is properly cited.

\begin{abstract}
Forms of selenium in bituminous coal, anthracite, and cokeite (natural coke) from Huaibei Coalfield, Anhui, China, have been determined by sequential solvent extraction. The selenium content in bulk samples is 4.0, 2.4, and $2.0 \mu \mathrm{g} / \mathrm{g}$ in bituminous coal, anthracite, and cokeite, respectively. The six forms of selenium determined by six-step solvent extraction are waterleachable, ion-exchangeable, organic matter-associated, carbonate-associated, silicate-associated, and sulfide-associated. The predominant forms of selenium in bituminous coal are organic matterassociated $(39.0 \%)$, sulfide-associated $(21.1 \%)$, and silicate bound $(31.8 \%)$; these three forms account for $92 \%$ of the total. The organic matter bound-selenium decrease dramatically from bituminous coal $(39.0 \%)$ to anthracite $(\mathrm{II} .6 \%)$ and to cokeite $(0 \%)$, indicating that organic matter bound selenium is converted to other forms during metamorphism of the coal, most likely sulfideform. The sulfide-associated form increased remarkably from bituminous coal (21.1\%) to anthracite $(50.4 \%)$ and cokeite $(54.5 \%)$, indicating the formation of selenium sulfide, possibly in pyrite during the transformation of bituminous coal to anthracite and cokeite. The silicate-associated selenium in bituminous coal (3I.8\%) is much higher than that in anthracite $(16.4 \%)$ and cokeite $(15.8 \%)$, indicating that silicate-associated selenium is partly converted to sulfide during metamorphism.
\end{abstract}

\section{Introduction}

China is the largest coal producer and consumer in the world. It has been estimated that more than $75 \%$ of the energy production in China is based on coal and more than 400 million people in China rely on coal for their domestic energy needs $[1,2]$. Due to the limited petroleum and natural gas reserves, and huge coal reserve in China, coal may remain to be a dominant energy source in China for many years to come [3-6]. Unfortunately, coal utilization may bring with it environmental and human health costs [7-9]. Many of the environmental and health problems attributed to coal combustion are due to mobilization of potentially toxic elements [7-11].

Selenium (Se) is one of the volatile elements in coal. During mining and utilization of coal Se is largely released into the environment with potential environmental and human health impacts [12-16]. There was massive waterfowl aberrance and death that happened in Kesterson Reservoir of California, and selenium-poisoning of the 
residents in Yutangba, Enshi, Hubei, China which provided impetus for study envitronmental geochemistry of Se. Although selenium metal has little toxicity, the selenide, selenite, and other selenium compounds such as selenium fluoride have a high toxicity. Because of high toxicity of Se and its compounds, Se is detrimental to plants and animals [9]. Human selenosis in some areas in China is attributed to the practice of using high-Se combustion residues as a soil amendment $[7,17,18]$. It is desirable to reduce Se content in coals prior to combustion. Selenium in coal is regarded as a source of Se for soils and plants which have caused selenosis in some areas of Serich coal and carbonaceous shale[7,9,19-24].

The mode of occurrence of an element is a description of the manner in which an element is chemically bound in the host material. In coal, elements can be associated with the inorganic constituents or with the organic constituents. The element's modes of occurrence can strongly influence its behavior during coal cleaning, weathering, leaching, combustion, and conversion $[25,26]$. These different modes of occurrence will cause the element to behave differently during coal cleaning and coal combustion and thus will have different environmental and human health impacts. Detailed knowledge of the forms of Se in coals is needed for a better understanding its behavior during coal processing and utilization, and consequent environmental impacts[18,27]. In this paper we studied the forms of Se in different ranks of coals from Huaibei coalfield, Anhui Province, China, by sequential solvent extraction.

\section{Samples and Methods \\ 2.I Geological Setting}

The Huaibei Coalfield is located in the northern Anhui province, China (Fig. 1 and Fig. 2) with longitude at $\mathrm{E} 115^{\circ} 58^{\prime}$ to $\mathrm{E} 117^{\circ} 12^{\prime}$ and latitude at $\mathrm{N} 33^{\circ} 20^{\prime}$ to $\mathrm{N} 34^{\circ} 28^{\prime}$. The Huaibei coalfield has an area of approximately $9,600 \mathrm{~km}^{2}$, in which $4,100 \mathrm{~km}^{2}$ are covered by Carboniferous and Permian coal-bearing strata. The Huaibei coalfield is unique because it is intruded by igneous bodies, and the coal is metamorphosed to a broad range of coal ranks from bituminous coal to anthracite and to cokeite (natural coke) by the influence of igneous heat source [28]. The annual production of the Huaibei Coalfield is over $30 \mathrm{Mt}$, which is mainly used for power generation and industrial boilers.

\subsection{Sample collection and preparation}

We collected samples of bituminous coal, anthracite and cokeite (natural coke) from Huaibei Coalfield. The samples were stored immediately in bags to prevent contamination and weathering. The samples were air-dried, milled and split until a representative sample of $0.5 \mathrm{~kg}$ was pulverized to pass the 100-mesh sieve and dried for
12 hours in a desiccator. The samples were analyzed for proximate and ultimate compositions at the Energy Institute, the Pennsylvania State University.

\subsection{Sequential extraction procedure}

The sequential extraction procedure was originally developed to analyze soil samples [29], and it is later modified for analyzing coal $[26,30]$. A variety of sequential extraction procedures have been successfully applied to coal [31-35]. Based on these studies, we devised a sequential extraction procedure for determining the forms of selenium in coals. The six-step sequential extraction procedure is outlined in Table 1. The forms of selenium in coals may be determined as water-leachable, ion-exchangeable, organic matter-associated, carbonate-associated, silicateassociated, and sulfide-associated.

\section{Results and discussion}

\section{I Proximate and ultimate analysis}

The results of proximate analyses (ash, moisture, volatile matter, and fixed carbon) and ultimate analyses $(\mathrm{C}, \mathrm{H}, \mathrm{N}$, $\mathrm{S}$, ash) are listed in Table 2. These data were designed to provide information on the technological performance of coal. The carbon content increases with increasing coal rank.

\subsection{Results of sequential solvent extraction}

The results of sequential extraction of selenium from three coals from Huaibei coalfield are listed in Table 3. The selenium content in the bulk sample of bituminous coal, anthracite and cokeite are 4.0, 2.43, and $2.0 \mu \mathrm{g} / \mathrm{g}$, respectively. The total recoveries of selenium from the six solvent extraction steps are $68.9 \%, 79.5 \%$, and $82.1 \%$, which are acceptable considering cumulative errors of extraction steps and analytical errors in the determination of Se in six fractions. The selenium content decreases with increasing rank of the three coals. There is a possibility that selenium was partially lost during metamorphism.

The amounts of selenium in each fraction extracted from the three coals are plotted in Figure 3.

\section{(I) Water-leachable Se}

The water-leachable Se is determined by refluxing the coal with double-distilled deionized water. During coal mining, storage, and transport, water-leachable Se is readily leached into the soil and ground water. The water-leachable Se in different ranks of coals of Huaibei coalfields are very low (Table 3 ) and the values are $0,0.063$, and 0.057 $\mu \mathrm{g} / \mathrm{g}$, respectively. In bituminous coal, water-leachable Se is lower than the detection limit, but is higher in anthracite and cokeite $(3.23 \%$ and $3.45 \%$, respectively, of the total). 


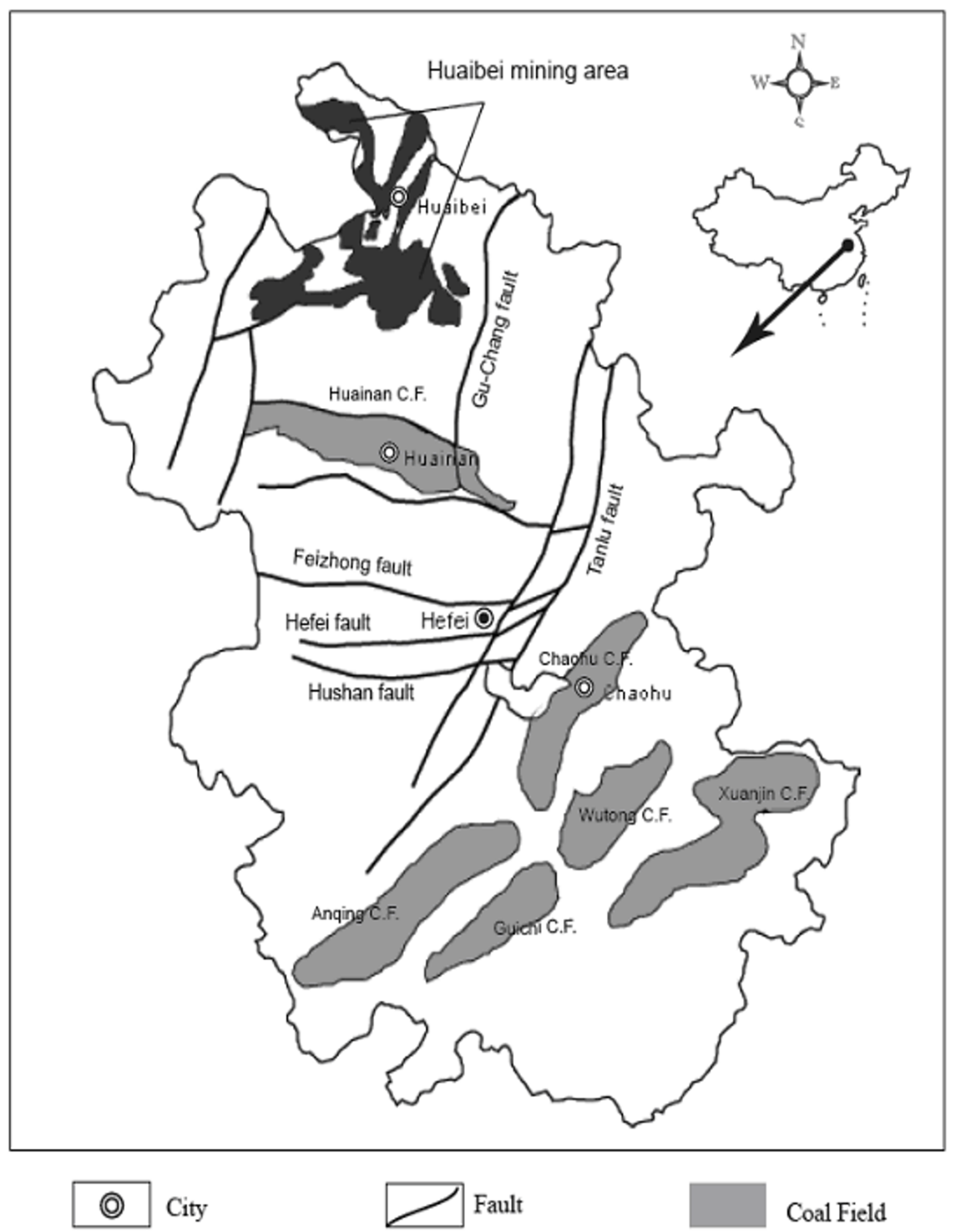

Figure I

Location of the Huaibei Mining District in Anhui Province, China. 


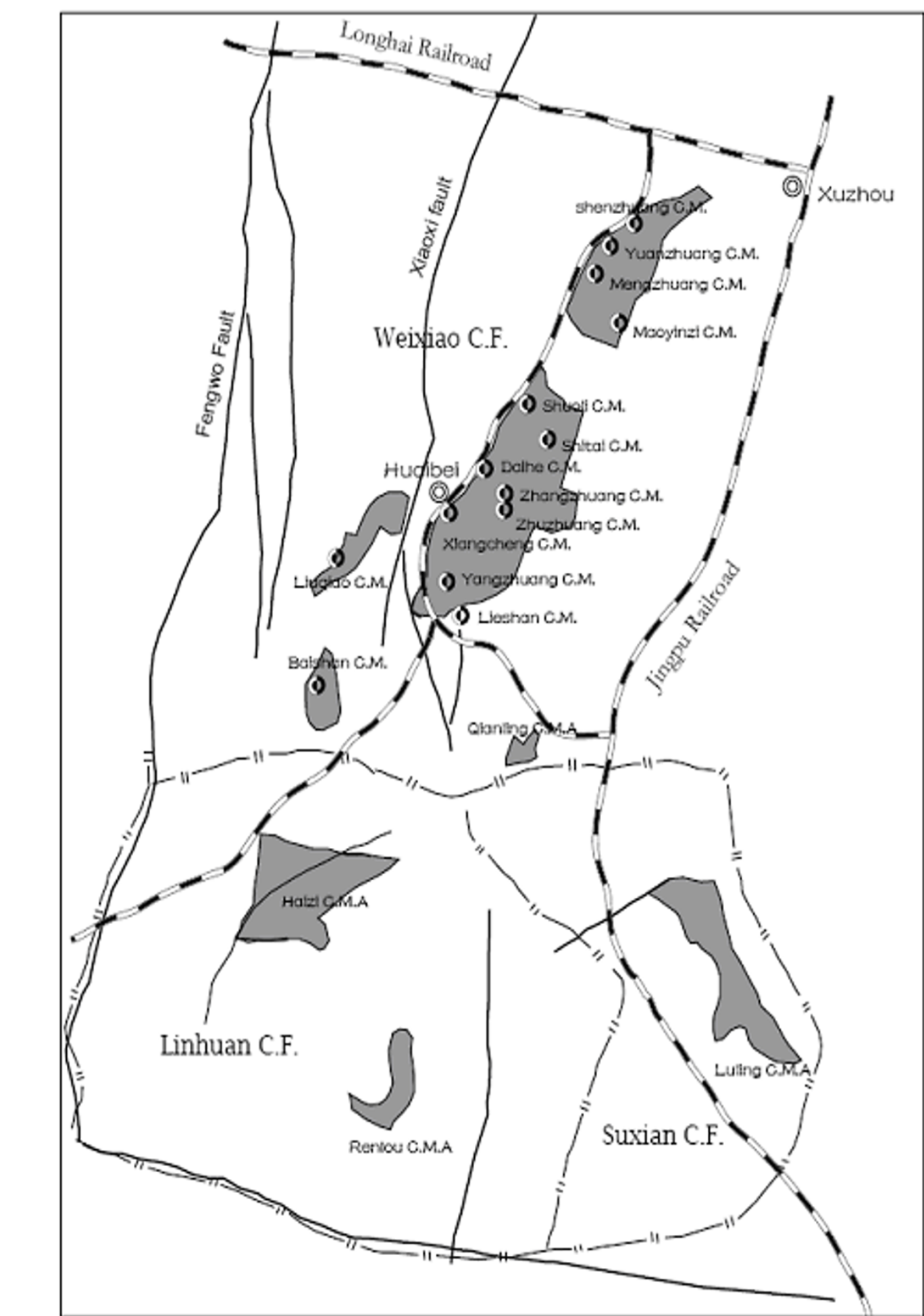

0 Coal Mine $\square$ Fault $\square$ Railroad $\square \| l-$ Coal Field Boundary $\square$ Coal Mining Area

Figure 2

Location of the coal mines in Huaibei mining district. 
Table I: Sequential chemical extraction procedure

\begin{tabular}{|c|c|}
\hline Form of selenium & Extraction method \\
\hline Water-leachable & $\begin{array}{l}\text { A 3-g sample of coal was transferred into a container. Add } 20 \mathrm{~mL} \text { of Milli-Q water at room temperature. Let } \\
\text { it stand for } 24 \mathrm{~h} \text {. The suspension was then centrifuged at } 3500 \mathrm{rpm} \text { for } 20 \mathrm{~min} \text {. }\end{array}$ \\
\hline lon-exchangeable & $\begin{array}{l}20 \mathrm{~mL} \text { of ammonium acetate }(\mathrm{I} \mathrm{N}) \text { was added to the dried residual solids at room temperature for } 24 \mathrm{~h} \text {, } \\
\text { suspension was then centrifuged at } 3500 \mathrm{rpm} \text { for } 20 \mathrm{~min} \text {. }\end{array}$ \\
\hline Organic matter-bound & $\begin{array}{l}\text { The dried residual solid was treated with } \mathrm{CHCl}_{3}\left(1.47 \mathrm{~g} / \mathrm{cm}^{3}\right) \text {. After } 24 \mathrm{~h} \text { of stirring at room temperature, a } \\
\text { float-sink separation was performed by centrifugation }(3500 \mathrm{rpm} \text { for } 20 \mathrm{~min}) \text {. The float fraction }(1.47 \mathrm{~g} / \mathrm{cm} 3) \\
\text { of the sample was dried at } 40^{\circ} \mathrm{C} \text {, then treated with } 12 \mathrm{~mL} \text { of an oxidizing mixture }\left(\mathrm{HNO}_{3}: \mathrm{HCl}=3: \mathrm{I}\right) \text { and } 3 \\
\mathrm{~mL} \mathrm{HF} \text { in a Telfon beaker which was put in a microwave oven (at } 600 \mathrm{~W} \text { for } 30 \mathrm{~min} \text {; at } 1200 \mathrm{~W} \text { for } 25 \mathrm{~min} \text {; } \\
\text { and at } 1200 \mathrm{~W} \text { for } 30 \mathrm{~min}) \text {. }\end{array}$ \\
\hline Carbonate-bound & $\begin{array}{l}\text { The sink fraction }\left(1.47 \mathrm{~g} / \mathrm{cm}^{3}\right) \text { was dried at } 40^{\circ} \mathrm{C} \text {, and then treated with } 20 \mathrm{ml} \mathrm{HCl}(0.5 \%) \text {. The suspension was } \\
\text { then centrifuged at } 3500 \mathrm{rpm} \text { for } 20 \mathrm{~min} \text {. }\end{array}$ \\
\hline Silicate-bound & $\begin{array}{l}\text { The dried residual solid was treated with } \mathrm{CHBr}_{3}\left(2.89 \mathrm{~g} / \mathrm{cm}^{3}\right) \text {. After } 24 \mathrm{~h} \text { stirring at room temperature, a float- } \\
\text { sink separation was performed by high-speed centrifugation }(5000 \mathrm{rpm} \text { for } 20 \mathrm{~min}) \text {. The float fraction }(2.89 \mathrm{~g} / \\
\left.\mathrm{cm}^{3}\right) \text { of the sample was dried at } 40^{\circ} \mathrm{C} \text {, and then treated with } 12 \mathrm{~mL} \text { of an oxidizing mixture }\left(\mathrm{HNO}_{3}: \mathrm{HCl}=\right. \\
3: \mathrm{I}) \text { and } 3 \mathrm{~mL} \mathrm{HF} \text { in a Telfon beaker which ws put in a microwave oven (at } 600 \mathrm{~W} \text { for } 30 \text { min; at I } 1200 \mathrm{~W} \text { for } \\
25 \mathrm{~min} \text {; and at I } 200 \mathrm{~W} \text { for } 30 \mathrm{~min}) \text {. }\end{array}$ \\
\hline Sulfide-bound & $\begin{array}{l}\text { The sink fraction }\left(2.89 \mathrm{~g} / \mathrm{cm}^{3}\right) \text { was dried at } 40^{\circ} \mathrm{C} \text {, and then treated with an oxidizing mixture }\left(\mathrm{HNO}^{3}: \mathrm{HCl}=\right. \\
3: \mathrm{I}) \text { and } \mathrm{HF} \text { in a Telfon which was put in a microwave oven (at } 600 \mathrm{~W} \text { for } 30 \mathrm{~min} \text {; at I } 200 \mathrm{~W} \text { for } 25 \mathrm{~min} \text {; and } \\
\text { at I } 200 \mathrm{~W} \text { for } 30 \mathrm{~min}) \text {. }\end{array}$ \\
\hline
\end{tabular}

\section{(2) lon-exchangeable Se}

Ion-exchangeable Se in coal is soluble in a solvent such as ammonium acetate $\left(\mathrm{NH}_{4} \mathrm{OAc}\right)$. The ion-exchangeable Se in bituminous coal, anthracite and cokeite are 0.128 , 0.138 , and $0.186 \mu \mathrm{g} / \mathrm{g}$, which are $4.66 \%, 7.14 \%$ and $11.34 \%$ of the total, respectively. In some previous studies, the water-leachable and ion-exchangeable Se are combined. In a study of Se in coal and overburden in the power River basin by [36], Se is present at the ppm level and occurs in at least six different forms. They found that the fraction of water soluble selenium in 14 overburden samples was $5-73 \%$, with an average of $22 \%$, of the total. Up to $50 \%$ of the selenium in the overburden samples was ion exchangeable (an average of $21 \%$ ). Selenium was sorbed by clays and other phases in the overburden samples. Querol et al. studied the forms of Se in a subbituminous Spanish coal with an ash yield of $26.5 \%$ by sequential solvent extraction. The found that the fraction of water-soluble and ion-exchangeable Se was less than $10 \%$ [37]. Yang studied the abundances and modes of occurrence of trace elements in the Late Permian coals in the Puan Coalfield, Guizhou, China, and found that the water-soluble Se fraction was about $0.03 \%$ [38].

\section{(3) Carbonate-associated Se}

The carbonate-associated Se content in bituminous coal, anthracite and cokeite of Huaibei Coalfield is 0.093, 0.224 , and $0.245 \mu \mathrm{g} / \mathrm{g}$, which are $3.36 \%, 11.6 \%$, and $14.9 \%$ of the total, respectively. The carbonate-associated selenium has previously been studied sequential extraction. Querol et al. found that the carbonate-associated fraction of Se was only less than 1\%[37]. Yang reported that carbonate-associated Se fraction was about $0.33 \%$. Their values are substantially lower than our results on Huaibei coals[38].

\section{(4) Sulfide-associated Se}

The sulfide-associated selenium in bituminous coal, anthracite, and cokeite is $0.581,0.975$, and $0.895 \mu \mathrm{g} / \mathrm{g}$, which are $20.1 \%, 50.5 \%$, and $54.5 \%$ of the total, respectively. The amount of sulfide-associated Se increases with increasing rank of coals. The sulfide-associated Se is the dominant mode of occurrence in anthracite and cokeite.

Table 2: Proximate and ultimate analyses and total Se concentrations of different ranks of coals

\begin{tabular}{ccccc}
\hline & $\%$ & Bituminous coal & Anthracite & Cokeite \\
\hline \multirow{2}{*}{ Ultimate analyses } & Carbon & 78.1 & 81.3 & 86 \\
& Hydrogen & 4.64 & 3.52 & 1.77 \\
& Nitrogen & 0.92 & 0.95 & 0.56 \\
Proximate analyses & Sulfur & 0.48 & 0.25 & 0.48 \\
& Moisture & 1.26 & 2.15 & 5.41 \\
& Volatile matter & 24.64 & 12.06 & 4.75 \\
& Ash & 14.51 & 13.14 & 6.94 \\
& Fixed carbon & 59.57 & 72.69 & 82.58
\end{tabular}


Table 3: Abundance of six forms of Se in sequential extraction fractions of the bulk sample (in $\mu \mathrm{g} / \mathrm{g}$ ) and fraction of each form of Se in three coals (in \%)

\begin{tabular}{|c|c|c|c|c|c|c|}
\hline & \multicolumn{2}{|c|}{ Bituminous coal } & \multicolumn{2}{|c|}{ Anthracite } & \multicolumn{2}{|c|}{ Cokeite } \\
\hline & Content $(\mu g / g)$ & Fraction (\%) & Content $(\mu g / g)$ & Fraction (\%) & Content $(\mu g / g)$ & Fraction (\%) \\
\hline Water-leachable & ND & 0.00 & 0.063 & 3.23 & 0.057 & 3.45 \\
\hline lon-exchangeable & 0.128 & 4.66 & 0.138 & 7.14 & 0.186 & 11.3 \\
\hline Organic matter-bound & 1.08 & 39.1 & 0.219 & 11.3 & ND & 0.00 \\
\hline Carbonate-bound & 0.093 & 3.36 & 0.224 & 11.6 & 0.245 & 14.9 \\
\hline Sulfide-bound & 0.581 & 21.1 & 0.975 & 50.4 & 0.895 & 54.5 \\
\hline Silicate-bound & 0.875 & 31.8 & 0.316 & 16.4 & 0.259 & 15.8 \\
\hline Total & 2.76 & 100 & 1.93 & 100 & 1.64 & 100 \\
\hline Bulk coal $(\mu g / g)$ & 4.00 & & 2.43 & & 2.00 & \\
\hline Recovery (\%) & 68.9 & & 79.5 & & 82.1 & \\
\hline
\end{tabular}

Abbreviation: ND, not detected

Both selenium and sulfur are Group 6a elements in the Periodic Table with similar covalent radii and electronegativities. Selenium may have diffused from non-sulfide phases into pyrite during coal metamorphism. Selenides may also form in anthracite and cokeite.

Previous studies have found a positive correlation between Se and S. Palmer and Lyons analyzed some European and American coals and found that pyrite has a higher Se content than illite, kaolinite, and quartz[39]. Zhang et al. found that the Se content of pyrite in anthracite from southwestern Guizhou is significantly higher than that in calcite and clay minerals. Statistical analysis of 24 samples of typical coals from main British coal basins shows that pyrite is the main carrier of Se [40,41]. A positive correlation between $\mathrm{Se}$ and $\mathrm{S}$ in the three anthracite samples from the i3B seam in the eastern Donbas suggests that $\mathrm{Se}$ is associated with pyrite [42]. Other studies also suggested that Se and S are highly correlated in coal and Se mainly occurs in pyrite from several coalfields [43-48]. Some researchers have reported sulfide-

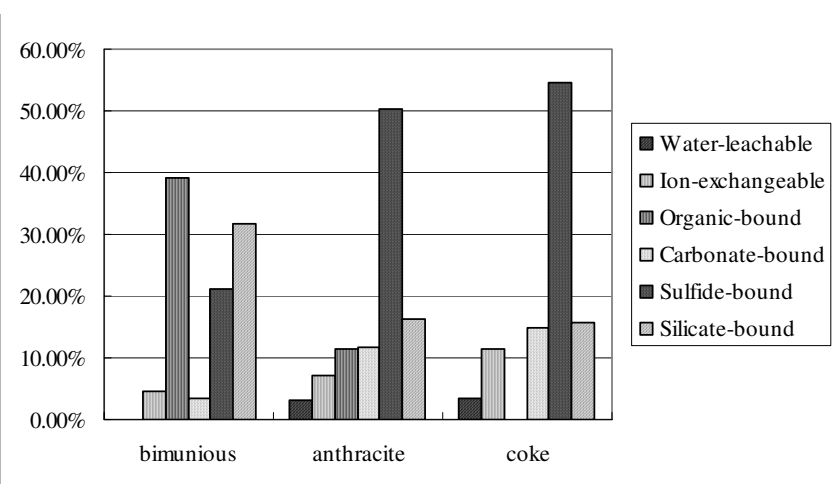

Figure 3

Histogram of fractions of Se forms determined by sequential extraction from three coals. associated selenium by sequential extraction. Liu performed a sequential extraction experiment to identify the forms of Se in coal as part of their study on volatilization of lignite, bituminous coal and anthracite[48]. The forms of selenium were determined as ion-exchangeable, organic matter-bound, sulfide-associated, and in residues. They showed that the sulfide-associated fraction of selenium accounts for $77 \%$ in lignite, $65 \%$ in bituminous coal, and $67 \%$ in anthracite. Yang has reported that sulfide-associated fraction of Se was $57.7 \%$. Thus, the sulfide-associated selenium is the dominant mode of occurrence in coals[38].

\section{(5) Organic matter-associated Se}

The organic matter-associated Se in bituminous coal, anthracite and cokeite samples from Huaibei Coalfield is $1.08,0.219$, and $0 \mu \mathrm{g} / \mathrm{g}$, respectively. The organic matterassociated fraction accounts for $39.1 \%, 11.3 \%$ of total Se in bituminous coal and anthracite, respectively (Figure 3). There is no organic matter-associated selenium in cokeite. When bituminous coal is converted to anthracite during metamorphism, the chemical structure of organic matter is changed, and selenium in the organic fraction may largely diffuse into other phases, most likely sulfides. Further, when anthracite is metamorphosed to cokeite, all selenium in the organic matter is incorporated into sulfides.

Other studies also showed that the organic matter-associated Se is a major mode of occurrence of Se in coal. Xu et al. performed sequential extraction tests and found that more than $70 \%$ of Se is associated with the organic matter[49]. Zhu et al. studied the modes of occurrence of Se in the Se-rich black shale in Yutangba area, Hubei, China, and found that Se resides dominantly in the residues and organic matter along with other forms of sulfide, selenide, and elemental Se[15,50,51]. Dreher and Finkelman reported that $10-20 \%$ of Se is in organic association in 
overburden sediments from a surface mine in Power River Basin, U.S.A[36].

\section{(6) Silicate-associated Se}

The silicate-associated Se content in bituminous coal, anthracite and cokeite samples from the Huaibei Coalfield is $0.875,0.316$, and $0.259 \mu \mathrm{g} / \mathrm{g}$ (Table 3 ), which are $30.2 \%, 16.4 \%$, and $15.8 \%$ of the total, respectively (Fig. $3)$. The silicate-associated Se fraction in our Huaibei samples are higher than the literature results, which may be related to the influence of magmatic intrusions in the Huaibei Coalfield.

Dreher and Finkelman reported that the silicate-associated fraction of Se was about $15 \%$ of the total in overburden sediments of a surface mine in Wyoming, U.S.A.[36] Zhang et al. found that silicate-associated Se is less than $1 \%[40]$. Palmer et al. found that their samples of U.S. coals have about 15\% silicate-associated Se fraction [52]. Yang determined abundances and modes of occurrence of trace elements in the Late Permian coals in the Puan Coalfield, Guizhou, China, and found that the silicate-associated fraction of Se was about 3.81\% of the total[38].

\section{Conclusion}

(1) We have performed sequential extraction tests to determine the forms of Se in three coals of bituminous, anthracite, and cokeite rank in the Huaibei Coalfield, Anhui, China. The Se content in bulk samples are 4.0, 2.4, and $2.0 \mu \mathrm{g} / \mathrm{g}$ in bituminous coal, anthracite, and cokeite, respectively. The Se content decreases with increasing rank of coals, which suggest that selenium may be partially lost during metamorphism.

(2) The results of six-step sequential extraction experiments show that the distribution of selenium forms varies with the rank. The fractions of water-leachable, ionexchangeable, carbonate-associated and sulfide-associated selenium increase with increasing rank. On the contrary, organic-bound and silicate-associated Se decreases with increasing rank.

(3) The predominant form of Se in bituminous coal is organic matter-associated $(39.1 \%)$, sulfide-associated $(21.1 \%)$, and silicate-bound (31.8\%). These three forms of Se account for $92 \%$ of the total.

The sulfide-associated fraction is $21.1 \%, 50.4 \%$, and $54.5 \%$ of total Se in bituminous, anthracite and cokeite, respectively. Sulfide-bond selenium is much higher in anthracite and cokeite than in bituminous coal, indicating the formation of sulfide and selenide minerals during metamorphim.
The organic matter-associated fraction accounts for $39.1 \%$ and $11.3 \%$ of total Se in bituminous coal and anthracite, but it is totally depleted in cokeite. During metamorphism, organic matter-associated selenium in bituminous coal diffuses into other phases, most likely sulfides, in anthracite and cokeite.

\section{Acknowledgements}

This work was supported by the National Natural Science Foundation of China (40772095) and the Anhui Natural Science Excellent Youth Foundation. We thank reviewers for constructive comments.

\section{References}

I. Chen BH, Hong CJ, Kan HD: Exposures and health outcomes from outdoor air pollutants in China. Toxicology 2004, 198:29|-300.

2. Florig HK: China's air pollution risks. Environmental Science Technology 1997, 31:274A-279A.

3. Ni B: New progress in high-precision and high resolution seismic exploration technology in coal industry of China. Acta Geological Sinica 2000, 74(2):3II.

4. Xu X, Chen C, Qi H: Development of coal combustion pollution control for $\mathrm{SO}_{2}$ and $\mathrm{NO}_{x}$ in China. Fuel Processing Technology 2000, 62:153-160.

5. Zhong Tang, Yang Wang: Efficient and environment friendly use of coal. Fuel Processing Technology 2000, 62:137-|141.

6. Liu G, Yang P, Peng Z, Chou C-L: Petrographical and geochemical contrasts and environmentally significant trace elements in marine-influenced coal seams, Yanzhou Mining Area, China. Journal of Asian Earth Sciences 2004, 23:49I-506.

7. Liu G, Zheng L, Duzgoren-Aydin NS, Gao L, Liu J, Peng Z: Health effects of arsenic, fluorine, and selenium from indoor burning of Chinese coal. Review of Environmental Contamination and Toxicology 2007, 189:89-106.

8. Liu G, Zheng L, Qi C, Zhang Y: Environmental geochemistry and health of fluorine in Chinese coals. Environmental Geology 2007, 52:1307-1313.

9. Liu G, Zhang Y, Qi C, Zheng L, Chen Y, Peng Z: Comparative on causes and accumulation of selenium in the tree-rings ambient high-selenium coal combustion area from Yutangba, Hubei, China. Environmental Monitoring and Assessment 2007, 133:99-103.

10. Wilson R, Colome SD, Spengler JD, Wislson DG: Health effects of fossil fuel burning. Ballinger Publishing, Cambridge, MA; I 980:392.

II. Swaine DJ, Goodarzi F: Environmental Aspects of Trace Elements in Coal. Kluwer Academic Publishers, The Netherlands; 1995:312.

12. Sun J, Jervis RE: Distribution characterization of trace elements during coal combustion. China Science Bulletin (A) 1986, 16: I 285-1294.

13. Clarke LB, Sloss LL: Trace elements from coal combustion and gasification. IEACR/49, IEA Coal Research, London; 1992: I I I.

14. Liu G, Zheng L, Peng Z: Distribution of hazardous trace elements during coal beneficiation. Geochimica et Cosmochimica Acto 2004, 67 (1 8 supplement): 522 .

15. Zhu J, Zuo W, Liang X, Li S, Zheng B: Occurrence of native selenium in Yutangba and its environmental implications. Applied Geochemistry 2004, 19:46I-467.

16. Yudovich YaE, Ketris MP: Selenium in coal: A review. International Journal of Coal Geology 2006, 67: I I2-126.

17. Zheng B, Hong T, Zhao W, Zhou H, Xia W, Su H, Mao D, Yan L, Thornton I: The Se rich carbonaceous siliceous rock and endemic Se poisoning in southwest Hubei, China. Chinese Science Bull etin 1992, 37(II):1027-1029.

18. Finkelman RB, Orem W, Castranova V: Health impacts of coal and coal use: possible solutions. International Journal of Coal Geology 2002, 50:425-443.

19. Yan $\mathrm{B}, \mathrm{Wu} \mathrm{T}$ : Investigation of the environmental selenium area in the Enxi autonomous prefecture. China Endemic Journal 1993, 12(3): 155-158. 
20. Mao D, Su H: Geographic factors affecting selenium poisoning in southwestern Hubei province. Hubei Journal of Preventive Medicine 1993, 4(3):23-25.

21. Mao D, Zheng B, Su H: The medical geography characteristics of Se poisoning in Yutangba. Endemic Diseases Bulletin 1997, I 2(2):59-6I.

22. Zheng B, Ding Z, Huang R, Zhu J, Yu X, Wang A, Zhou D, Mao D, Su $H$ : Issues of health and disease relating to coal use in southwestern China. International Journal of Coal Geology 1999, 40:119-132.

23. Zhu J, Ling H, Wang M, Li S, Su H: Distribution, transportation and bioavailability of selenium in Yutangba, Hubei province, China. Acta Pedologica Sinica 2005, 42(5):838-843.

24. Finkelman RB: What we don't know about the occurrence and distribution of trace elements in coals. The Journal of Coal Quality 1989, 8:3-4.

25. Finkelman RB: Modes of occurrence of potentially hazardous elements in coal: levels of confidence. Fuel Processing Technology 1994, 39:21-32.

26. Finkelman RB: Potential health impacts of burning coal beds and waste banks. International Journal of Coal Geology 2004, 59:19-24.

27. Han S: Coal-forming Conditions and Coalfield Prediction in Huaibei-Huainan Region. Geological Publishing House, Beijing, China; 1990:234.

28. Tessier A, Campbell PGC, Bisson M: Sequential extraction procedure for the speciation of particulate trace metals. Analytical Chemistry 1979, 5 I:844-851.

29. Finkelman RB, Palmer CA, Krasnow MR, Aruscavage PJ, Sellers GA, Dulong FT: Combustion and leaching behavior of elements in the Argonne Premium Coal Samples. Energy and Fuels 1990, 4:755-766

30. Bool LE, Helble J]: A laboratory study of the partitioning of trace-elements during pulverized coal combustion. Energy Fuels 1995, 9:880-887.

31. Cavender PF, Spears DA: Analysis of forms of sulfur within coal, and minor and trace element associations with pyrite by ICP analysis of extraction solutions. In Coal Science, Vol Coal Science Technology Volume 24. Edited by: Pajares JA, Tascon JMD. Amsterdam: Elsevier; 1995:1653-1656.

32. Palmer CA, Mroczkowski SJ, Kolker A: Chemical analyses and modes of occurrence of selected trace elements in a Powder River Basin coal and its corresponding simulated cleaned coal. U.S. Geological Survey, Open-File Report 00-323; 2000:52.

33. Davidson RM: Modes of occurrence of trace elements in coal. International Energy Agency Coal Reserch, London; 2000:36.

34. Zheng L, Liu G, Qi C, Zhang Y, Wong Minghong: The use of sequential extraction to determine the distribution and modes of occurrence of mercury in Permian Huaibei coal, Anhui Province, China. International Journal of Coal Geology 2007.

35. Dreher GE, Finkelman RB: Selenium mobilization in a surface coal mine. Powder River Basin, Wyoming, USA. Environmental Geology and Water Sciences 1992, 19:155-167.

36. Querol X, Fernández-Turiel JL, López-Soler A: Trace elements in coal and their behaviour during combustion in a large power station. Fuel 1995, 74:331-343.

37. Yang JY: Concentrations and modes of occurrence of trace elements in the Late Permian coals from the Puan Coalfield, southwestern Guizhou, China. Environmental Geochemistry Health 2006, 28:567-576.

38. Palmer CA, Lyons PC: Selected elements in major minerals from bituminous coal as determined by INAA: Implications for removing environmentally sensitive elements from coal. International Journal of Coal Geology 1996, 32:151-166.

39. Zhang J, Ren D, Xu W, Zhao F: Advances in the studies of selenium in coal. Coal Geology and Exploration 1999, 27:16-19.

40. Spears DA, Zheng Y: Geochemistry and origin of elements in some UK coals. International Journal of Coal Geology 1999, 38:161-179.

41. Kizilstein LYa, Shokhina OA: Geochemistry of selenium in coal: environmental aspect. Geokhimiya 200I, 4:434-440.

42. Martinez-Tarazona MR, Vega JMG, Garcia AB: Pyrite and trace elements in high rank coals. In Proc 9th International Conference on Coal Science Volume I. Edited by: Ziegler A, et al. DGMK, Essen; 1997:397-400.
43. Huang $W$, Yang $Q$, Tang $D$, Kang $X$, Liu D: Trace element geochemistry of the coals in the Taiyuan formation from Zaozhuang coalfield. Journal of Graduate School of China University of Geoscience 2000, |4:6|-68.

44. Lu XW: Study on selenium contents and specification and its environmental effect in coal of all coal forming periods of Sha'anxi Province. Journal of Arid Land Resources and Environment 2004, I 8:27-3I

45. Wu ZY, Li YH, Zhou YC: Geochemical behavior of trace elements in coals in Baishan area, Jilin Province. Coal Geology and Exploration 2004, 32:8-10.

46. Li DH, Tang YG, Chen K, Deng T, Cheng FP, Liu D: Distribution of twelve toxic trace elements in coals from southwest China. Journal of China University of Mining and Technology 2006, 35:15-20.

47. Liu SQ, Wang YT, Yu L, Oakley J: Volatilization of mercury, arsenic and selenium during underground coal gasification. Fuel 2006, 85: I550-1558.

48. Xu WD, Zeng RS, Ye DN, Querol X: Distribution and environmental impact of selenium in wastes of coal from a power plant. Environmental Science 2005, 26:64-68.

49. Zhu J, Zheng B: Distribution of selenium in mini-landscape of Yutangba, Enshi, Hubei Province, China. Applied Geochemistry 2001, 16:1333-1344.

50. Zhu JM, Zheng BS, Su HC, Li HC, Mao D, Lei P, Finkelman RB: New occurrence of native selenium and its preliminary investigation. Geochimica 200I, 30:236-24I.

5I. Palmer CA, Kolker A, Finkelman RB, Kolb KC, Mroczkowski SJ, Crowley SS, Belkin HE, Bullock JH Jr, Motooka JM: Trace elements in coal - modes of occurrence analysis. U.S. Geological Survey; 1997.
Publish with Biomed Central and every scientist can read your work free of charge

"BioMed Central will be the most significant development for disseminating the results of biomedical research in our lifetime. "

Sir Paul Nurse, Cancer Research UK

Your research papers will be:

- available free of charge to the entire biomedical community

- peer reviewed and published immediately upon acceptance

- cited in PubMed and archived on PubMed Central

- yours - you keep the copyright 